\title{
New Responses to Emerging Environmental Problems in USA
}

The Conservation Foundation, a non-profit group based in Washington, DC, conducts research on emerging issues in environmental and resource management. In June of this year, the Foundation published a report entitled State of the Environment: An Assessment at Mid-Decade*-a comprehensive, independent assessment of the conditions prevailing in air, water, hazardous waste, agriculture, and other resource issues.

In its study, the Foundation argues that US environmental laws need readjusting as more is learned about how pollutants behave in the environment, and as measuring capabilities improve to detect minute traces of toxic chemicals. 'The understanding of environmental problems in the early 1970 s, when the framework for current US environmental programs was established, has been superseded by knowledge gained during the past decade,' the report says.

State of the Environment documents significant progress in environmental areas where laws and institutions have been explicitly devised to address specific problems. Most conventional air pollutants-for example, sulphur dioxide, nitrogen dioxide, carbon monoxide, and particulates - no longer pose a health threat to nearby communities. The majority of US rivers are suitable for fishing and swimming. Exposure to some specific toxic substances-lead, PCBs, and DDT, for instance-has declined. But this progress, the Foundation warns, should not obscure many points of controversy in ongoing environmental programmes. Thus budget cuts at the national and state levels over the past few years have weakened environmental programmes, while environmental monitoring and research are often inadequate to evaluate existing programmes or to identify new problems. Many potentially harmful toxic substances are not adequately monitored, and accordingly no means are provided of assessing any risks which they may pose.

The report discusses in depth several issues such as risk assessment, water resources, and intergovernmental relations. It particularly emphasizes the problem of 'cross-media' pollution - that is, the tendency of pollutants to move readily from one medium, such as air or water, to another, such as soil. An example illustrates the problem: a municipal wastewater treatment-plant removes a heavy-metal from city wastewater, thus preventing it from polluting a nearby stream; the waste sludge containing the pollutant is deposited in a landfill, however, from which the heavy-metal infiltrates ground-water, the source of drinking-water for the community. 'Instead of reducing human and environmental exposure to toxics,' State of the Environment concludes, 'much of the existing control effort may simply be shifting pollutants from one part of the environment to another.'

What can be done about cross-media pollution? To address this question, the Conservation Foundation began last year a three-years' research project to consider options for redesigning pollution control programmes to reflect the cross-media phenomenon. Drawing on research findings and experience in implementing environmental programmes, this effort is considering how United States regulators can establish and enforce standards for air and water pollution that take into account the movement of pollutants through different parts of the environment.

In addition to its research on emerging issues, the Conservation Foundation plays an active role in addressing some of the issues which it investigates. The Foundation sponsors dialogues on timely issues, drawing together repesentatives from environmental groups, business, government, and other sectors. One dialogue group, involving leaders in the chemical industry and the environmental community, considered over nearly a year how to speed the cleanup of toxic-waste dumps. Out of this effort came a proposal to create a non-profit corporation that, subject to the review and approval of the US Environmental Protection Agency (EPA), will bring additional resources to bear on the waste-site problem. The new corporation, Clean Sites, Inc., which was officially established on 31 May 1984 in Washington, DC, will convene parties responsible for waste at a given site to negotiate a plan for financing cleanup of the site. Clean Sites will also prepare technical plans for cleanups, and will oversee actual cleanup work. Russell Train, president of World Wildlife Fund-US and former Administrator of EPA, will be Chairman of the Board of Directors of this new institution.

\section{GoRdon BINDER \\ The Conservation Foundation \\ 1717 Massachusetts Avenue \\ Washington \\ DC 20036, USA.}

\footnotetext{
*Available from Bowker Publishing Co., PO Box 5, Epping, Essex CM16 4BU, England, UK.
}

\section{Vance Bibliographies: Literature Guide and Research Tool}

Since 1978, under the editorship of Mary Vance, Vance Bibliographies has published 'Public Administration Series: Bibliography', and 'Architecture Series: Bibliography'. The series are designed for college and professional library use, and have received repeated commendations for their usefulness.

Public Administration Series: Bibliography:-Covers a wide range of topics, the main criterion for selection of each being whether it involves an issue in which public administration was, is, will be, or should be, involved. Thus the series covers policy, economics, taxation, regulation, education, environment, energy, transportation, administration, political science, employment, criminal justice, law, social services and programmes, health care, geography, land, recreation, urban and regional planning, etc. - many of which are highly environmental in their impress. The PA Series topics, to a large extent, are selected with an American focus because public administration in North America is based widely upon culture and existing government infrastructure. The PA Series is primarily used in the United States and in countries with similar public administration needs.

Architecture Series: Bibliography:-Also covers a wide range of topics, the main criterion for selection of each being whether it is one in which architects, physical planners, or landscape architects, are or should be interested. The series covers design, aesthetics, graphics, housing, special buildings, planning, environment, building materials, styles, construction, history, historic preservation, individual architects and architectural firms, individual elements of buildings, regional architecture, site selection, landscape architecture, etc., architecture being of course universal in scope. 
Most of our bibliographies are compiled by librarians and university faculty members, though a significant number are compiled as a research by-product by professionals and scholars. We do not maintain an in-house staff of bibliographers. The bibliographies range widely in style and length, owing to the nature of a particular topic and also to the resources of the compiler. A sociologist's bibliography and an architect's bibliography do not follow the same entry-format, because their disciplines require different bibliographic styles. Therefore we ask only that each compiler do a good job of covering his or her topic, that the form and style be consistent within the bibliography, and that citations be accurate and complete enough to locate each item in any good research library or to borrow on interlibrary loan from such a library. The title must be descriptive, and we think an introduction is useful to the reader while also giving the compiler a place for his or her own summary, ideas, procedures, and subject limitations.

After a manuscript is accepted for publication, it is given an issue number, ISBN number, and imprint date; thereafter it is retyped and published as a booklet. The issues are priced ac- cording to pagination, with a minimum price of $\$ 2.00$ and a maximum of $\$ 20.00$. Standing orders are shipped and billed each month with a $20 \%$ discount from list price. Each series averages 20 issues per month. We do not advertise any issue prior to publication. Our bibliographies may be ordered directly from us or through a dealer. Orders can be prepaid or invoiced. We do not charge for postage and handling on foreign surface-mail-rate shipments valued at over $\$ 20.00$, but actual postage costs for airmail or first class shipments are added to the invoice for the faster shipping if desired.

For a list of bibliographies available for purchase, write to: Vance Bibliographies, P.O. Box 229, Monticello, Illinois 61856 , USA. If you are interested in contributing to either series, write to the undersigned.

JUdith VANCE, Publisher VANCE Bibliographies P.O. Box 229 Monticello Illinois 61856, USA.

\section{New 'Laser' Herbicides Kill Plants without Damaging the Environment}

Scientists have recently discovered a potent class of environmentally safe plant-killing substances-called 'Iaser' herbicides-whose destructive force is unleashed by sunlight. The scientists, from the University of Illinois, said their discovery is 'a whole new mechanism of killing (undesirable) plants'. They said tests of 'laser' herbicides, which are made of readilyavailable chemicals, showed that they destroy many weeds which are troublesome to farmers-while leaving crops such as maize, wheat, barley, and oats, unharmed. The substances are called 'laser' herbicides because they are activated by light and can be targeted specifically on undesirable plants.

'Laser' herbicides work, the scientists said, by causing a plant to stockpile light-sensitive chemicals whose chain-reaction of destruction and death is triggered by the rising sun. 'The plants literally commit suicide,' said Professor Constantin A. Rebeiz, a plant physiologist and leader of the research group: 'This is a breakthrough in herbicide design, both conceptually and from an environmental impact standpoint. Our research has been aimed at the design of herbicides that would kill undesirable plants via a predetermined and novel mode of action, based on sound biochemical principles.'

Professors Rebeiz and Herbert J. Hopen (a herbicide specialist and Professor of Vegetable Crops), said that as the herbicides' principal ingredient is a biodegradable chemical found in all plants and animals, it should be environmentally safe. The development of these 'laser' herbicides takes advantage of recent advances in the understanding of the greening process in plants-the way plants make chlorophylls, the green pigments of plants that catalyze photosynthesis, the mechanism by which plants convert sunlight and carbon dioxide into plant material and so feed the world.

The prime ingredient of the 'laser' herbicide tested by the Illinois research workers is delta-aminolevulnic acid, or ALA. An amino-acid found in all plant and animal cells, ALA is a natural building-block in the chemical construction of chlorophyll. Specifically, ALA is used by plants to make tetrapyrroles, a group of extremely light-sensitive chemicals that form chlorophyll in the presence of sunlight, Professor Rebeiz said. The amounts and kinds of tetrapyrroles that are formed and accumulated depend on the species of plant. The differences among plants in their capacity to destroy or convert the excess tetrapyrroles into harmless substances determines which plants would be most affected.

The ALA-based 'laser' herbicide is sprayed just before nightfall and absorbed by the plants. Spurred on in the darkness by a chemical activator in the herbicide, new tetrapyrroles are formed quickly from the added ALA. As no light is present at night, the tetrapyrroles are not processed into chlorophyll, and they build up into a reservoir of light-sensitive chemicals.

The situation resembles that of a keg of explosive black powder being filled a little at a time, where sunlight can be thought of as a match, Professor Rebeiz said: 'If you let these biochemical precursors accumulate slowly and "burn" them a little at a time as they accumulate, as in daylight, then you won't have a problem-only a steady fizzle; but if you allow them to build up in large amounts and ignite them all at once with sunlight, then the whole thing is going to "explode". Moreover, by allowing them to accumulate at night, you are letting them form a critical mass. The plant has allowed the black powderkeg to build up, and in the morning you are putting a match to it,'Professor Rebeiz explained.

'What happens in the first few hours after the sun rises is nothing short of an escalating chain-reaction of destruction', Professor Rebeiz said. 'When sunlight hits the light-sensitive stockpile of tetrapyrroles, a rapid chemical reaction is set in motion that leads to the formation of free radicals. The free radicals destroy the tissue structure in the plant's cells by creating more and more free radicals and more and more damage, until cell membranes leak. Dehydration and death follow.' In addition to providing an effective new class of herbicides, the discovery of 'laser' herbicides is important for its new concept in herbicide design and development, the scientists said.

Work on laser herbicides began in December 1982, just after another group led by Professor Rebeiz discovered a chemical that inhibited plants from becoming green and Professor Hopen then discussed how to develop a new herbicide based on the discovery. Their collaboration produced the series of experiments that led to the 'laser' herbicide development. Now they are attempting to identify chemicals that would induce plants to increase production of their own ALA. Announcement of the above finding was made jointly by the National Science Foundation and the University of Illinois, the research being financed jointly by the former's Metabolic Research Programme and the latter's Agricultural Research Station.

RALPH KAZARIAN National Science Foundation 1800 G Street Washington DC 20550, USA. 